\title{
The First Spawn-taking from Broodstock Yellowtail Cultured with Extruded Dry Pellets
}

\author{
Takeshi Watanabe, ${ }^{* 1}$ Visuthi Verakunpiriya, ${ }^{* 1}$ Keiichi Mushiake, ${ }^{* 2}$ \\ Kazutoshi Kawano, ${ }^{* 2}$ and Izumi Hasegawa*2 \\ ${ }^{*}$ Laboratory of Fish Nutrition, Department of Aquatic Biosciences, \\ Tokyo University of Fisheries, Konan, Minato, Tokyo 108, Japan. \\ ${ }^{*}$ Komame Station of Japan Sea-Farming Association, Komame, \\ Otsuki, Hata, Kochi 788-03, Japan.
}

(Received August 24, 1995)

This experiment was conducted to gather some basic information necessary for the development of quality dry pellets for yellowtail broodstock. The spawning results of yellowtail broodstock fed softdry pellets (SDP) and Oregon type of moist pellets (MP) and/or frozen raw fish (RF) were compared.

Yellowtail having an average body weight of $3.7 \mathrm{~kg}$, which had been cultured with extruded dry pellets (EP) from juvenile stage (about $0.89 \mathrm{~g} \mathrm{BW}$ ) for 20 months, were divided into two lots of 25 fish each and stocked into the $5 \times 5 \times 5 \mathrm{~m}$ floating net cages. The first group was fed SDP containing $10 \%$ krill meal and the second group was fed MP. Yet another lot of 25 broodstock fish which had been fed EP for 14 months and subsequently fed RF for 6 months, continued to receive the same food until spawning manipulation. Egg collection was undertaken after brood fish were transferred to the $65 \mathrm{~m}^{3}$ spawning tanks on land and they were induced to spawn by injecting $600 \mathrm{IU}-\mathrm{HCG} / \mathrm{kg}$-fish BW.

Two days after HCG injection, brood fish from SDP and MP groups started to spawn and continued for 8 and 10 days, respectively, but broodstock fed RF spawned only once during this period. The SDP group produced only half of the total number of eggs obtained from the MP group. However, the quality of eggs were found to be superior to those obtained from the MP group. Out of the total eggs produced, the percentages of buoyant and fertilized eggs and total hatch were respectively about 59, 57 and 47 for the SDP group; 39, 34 and 18 for the MP group and 36, 3 and-(not determined) for the RF group.

The preliminary results obtained in this experiment have clearly indicated that broodstock yellowtail can be cultured with extruded dry pellets from the juvenile stage under captivity. Further this would enable the development of quality dry pellets for yellowtail broodstock in the near future.

Key words: yellowtail, broodstock diets, extruded dry pellets, egg quality

One of the economically important cultured fish of Japan is the yellowtail Seriola quinqueradiata. The total production of yellowtail constitutes a major share of the marine finfish produced. ${ }^{\text {) }}$ However, the seedling requirements are met by larvae and juveniles gathered from nature, often in limited numbers. On the other hand, millions of hatchery-reared juveniles are being released into the coastal waters every year by the Japan Sea-Farming Association (JASFA) to promote coastal fisheries. An ideal situation would prevail when the natural juveniles are permitted to be recruited into the natural population, and the hatchery-produced juveniles meet the requirement for mariculture. Therefore, it is necessary to cultivate the yellowtail broodstock to ensure a year-round seed supply, rather than seasonal, in order to meet the ever-growing demand of the aquaculturist. To obtain quality fertile eggs which would yield high larval survival and growth rates, a superior diet formulated on the basis of the nutritional requirement of brood fish during gonadal development is required.

A significant achievement in this direction was made by the NRIA (National Research Institute of Aquaculture, Japan) employing the so-called Oregon type moist pellets
(MP). ${ }^{2)}$ Their results indicated that MP can be used as a yellowtail broodstock diet with an improvement in larval production. However, the drawbacks were: 1) the large fluctuation in the quality of MP prepared by mixing formulated mash with raw fish, depending on the principal ingredient - raw fish; 2) the low shelf-life of MP, necessitating its preparation several times based on the availability of

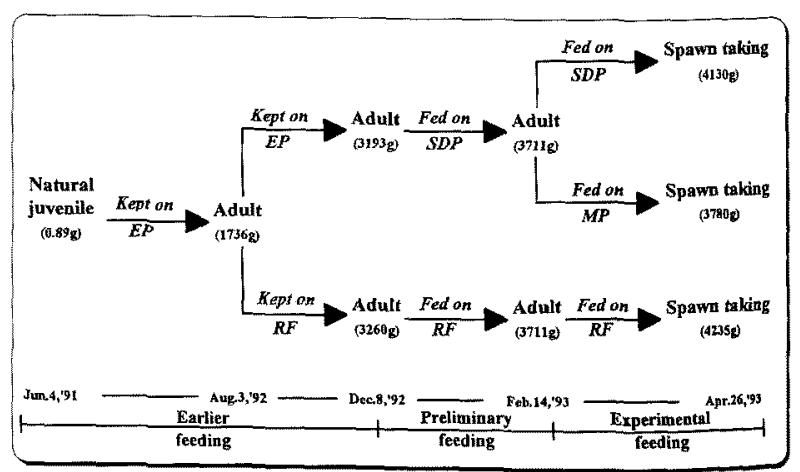

Fig. 1. Rearing history of yellowtail broodstock used in the experiment. 
raw fish; 3) the requirement for high power and costly equipments such as pellet-machine and cold storage facilities; and 4) the ecologically undesirable characteristic of comparatively higher aquaculture waste loading. Considering these factors, the dry pellet has a distinct gain over the MP, and this accounted for the success of the soft-dry pellets (SDP) which was developed for yellowtail. ${ }^{3)}$

Taking advantage of the qualities of SDP, this experiment aimed to develop dry pellets (EP) for yellowtail broodstock. The basic data obtained in this research could help the further development of a superior quality EP for broodstock yellowtail.

\section{Materials and Methods}

\section{Rearing Background of Yellowtail Broodstock}

As shown in Fig. 1, the yellowtail broodstock used for this experiment had been completely fed on dry pellets from the juvenile stage to adult. Juvenile yellowtail gathered from nature, and having an average body weight of $0.89 \mathrm{~g}$ were obtained from Katada Fisherman's Cooperative Association and kept at the Wakayama Prefectural Institute of Fisheries. They were fed on a commercial EP (Sakamoto Feed Co., Ltd.) for 14 months until they grew up to about $1736 \mathrm{~g}$ and they were then divided into 2 lots. The first lot continued to be fed the EP for another 4 months (EP group) whereas the second lot was offered raw fish during the same period (RF group). Both EP and RF groups were transferred from the Wakayama Prefectural Institute of Fisheries to the Komame Station of JASFA, Kochi Prefecture and stocked into $5 \times 5 \times 5 \mathrm{~m}$ floating net cages which were installed in the Komame Bay, close to the Station. The broodstock were transported by sea and carefully handled causing minimal stress.

\section{Experimental Rearing of Yellowtail Broodstock}

The preliminary feeding commenced after broodstock arrived at the Komame station. The fish of EP group, having an average body weight of $3193 \mathrm{~g}$ were introduced to a commercial yellowtail SDP (Sakamoto Feed Co., Ltd.) while those from RF group, having an average body weight of $3260 \mathrm{~g}$ still continued to feed on raw fish for another 2 months.

The feeding experiment was conducted in the $5 \times 5 \times 5 \mathrm{~m}$ floating net cages. The fish of EP group were divided into 2 lots, 25 fish each, and were fed one of the experimental diets, SDP or MP. The fish of RF group continued to receive the frozen raw fish. Each group was fed a restricted ration of the respective test diet once a day, every two days. The feeding rate was about $3.0 \%$ of body weight for the MP and SDP groups while it was adjusted at about $5.5 \%$ of body weight for the RF group.

Assessment of spawning was made after $2 \frac{1}{2}$ months of feeding experiment. Prior to this, trial fish were separately transferred to the $65 \mathrm{~m}^{3}$ spawning concrete tanks on land and arranged at 1:1 sex ratio by stocking 5 males and $5 \mathrm{fe}$ males each per tank. The breeding manipulation was performed 5 days after acclimatizing the brood fish, by injecting HCG (human chorionic gonadotropin) at a dosage of $600 \mathrm{IU} / \mathrm{kg}$-fish body weight to induce spawning in all the male and female brood fish of each tank. As indicated by Umeda $^{4}$ on ovarian maturation of yellowtail, water tem- perature was maintained at about $19^{\circ} \mathrm{C}$. The spawning conditions and the procedures adopted for the induced spontaneous spawning were described previously. ${ }^{2,5,6)}$

\section{Experimental Diets}

SDP was used as a test diet in this experiment and the other two feeds, MP and RF served as the controls. The compositions of the experimental diets are shown in Table 1. Diet 1, the raw fish, offered was either mackerel Scomber japonicus or jack mackerel Trachurus japonicus. They were purchased from frozen fish industries near the Komame Station (JASFA) and stored in a cold room at the station until use. They were chopped into a suitable size and mixed with $1 \%$ vitamin premix (Product of Pfizer) before being fed to the trial fish. Diet 2, the moist pellet MP, was a modified NRIA formulation and contained $65 \%$ fish meal and $10 \%$ squid meal as protein sources, in addition to pollack liver oil $(6 \%)$ and squid liver oil $(6 \%)$ as lipid sources. The MP was freshly prepared at the Komame Station every week by mixing raw fish with the formulated mash (modified NRIA formula) at a ratio of $1: 1$. The ingredients were thoroughly mixed and pelleted to a suitable size and finally $3 \%$ squid liver oil and $3 \%$ synthetic astaxanthin powder (employed as the carotenoid source in place of krill oil extract used by NRIA) were added just before being fed to the trial fish. However, it was later found that $\beta$-carotene (a water soluble powder containing $3 \% \quad \beta$-carotene) was mis-supplemented instead of astaxanthin. Therefore, the MP contained a relatively high amount of $\beta$-carotene. Diet 3 , the soft-dry pellet, was the diet developed by Watanabe and co-workers. ${ }^{3)}$ The SDP contained 55\% local sardine meal as the main protein source and $10 \%$ krill meal was added to enhance the pigmentation of skin. ${ }^{7}$ The mineral and vitamin mixtures were incorporated to satisfy the requirement of yellowtail. ${ }^{8,9)}$ This experimental SDP was kindly prepared by Sakamoto Feed Co,. Ltd. using a twin screw extruder. ${ }^{3)}$

Table 2 shows the proximate compositions of each experimental diet. The vitamin $E$ content which is important for gonadal development was very low in RF, probably due to the oxidization of vitamin $\mathrm{E}$ during storage. As usual, the water content of RF was high (74\%). Similarly, the moisture content of MP that was prepared with raw fish was also high ( $41 \%)$. With the exception of vitamin $E$, the content of other nutrients in all the experimental diets

Table 1. Composition of the experimental diets

\begin{tabular}{|c|c|c|c|}
\hline \multirow{2}{*}{$\begin{array}{l}\text { Ingredients } \\
(\mathrm{g} / 100 \mathrm{~g})\end{array}$} & \multicolumn{3}{|c|}{ Diet no. } \\
\hline & 1 & 2 & 3 \\
\hline Local sardine meal & & & 55 \\
\hline Krill meal & & & 10 \\
\hline Wheat fiour & & & 12 \\
\hline Wheat gluten & Frozen raw fish ${ }^{* 1}$ & Moist pellet ${ }^{* 2}$ & 3 \\
\hline Potato starch & & & 3 \\
\hline Vitamin mixture ${ }^{* 3}$ & & & 2 \\
\hline Mineral mixture ${ }^{* 3}$ & & & 2 \\
\hline Pollack liver oil & & & 13 \\
\hline
\end{tabular}

\footnotetext{
*) Mackerel or Jack mackerel were used.

*2 The formula was developed by NRIA. ${ }^{2}$

*3 Takeda ${ }^{\text {g) }}$
} 
expressed on a dry matter basis seemed to satisfy the requirement for adult yellowtail., ${ }^{3,8-10)}$

Investigation of Spawning and Evaluation of Egg Quality

Eggs produced by female brood fish of each group were gathered in the collecting nets fixed to the over-flow system. They were harvested every day from 17:00 to 09:00 the next morning during the experimental period as long as the brood fish continued to produce eggs. The estimation of maturation and the procedures for collection, estimation and evaluation of eggs were completed as per the previous description. ${ }^{6)}$

The determination of egg and oil-globule diameters, the number of oil-globules and fertilization rate were performed for the buoyant eggs using a profile projector (Nikon). The rate of hatching was calculated by counting the larvae hatched from every group during each spawning day.

\section{Results and Discussion}

Table 3 shows the results of the feeding experiment for each test diet ( 22 days feeding, $2 \frac{1}{2}$ months rearing period). Weight of broodstock fed test diets $(3.8-4.3 \mathrm{~kg})$ did not change much from the initial stocking weight $(3.7 \mathrm{~kg})$ and this lack of growth might be due to the short-term feeding, apart from the utilization of nutrients for gonadal development. The size of broodstock used in this experiment was relatively small when compared to the commonly used spawners which usually weighed more than $8 \mathrm{~kg}$ as reported by Mushiake et al. ${ }^{2,5,6)}$ This might have affected the

Table 2. Proximate composition and n-3 HUFA, VA and VE contents of the experimental diets

\begin{tabular}{lrrr}
\hline & \multicolumn{3}{c}{ Experimental diets } \\
\cline { 2 - 4 } & $\mathrm{RF}$ & $\mathrm{MP}$ & $\mathrm{SDP}$ \\
\hline Proximate composition (\%) & & & \\
$\quad$ Crude protein & 18.5 & 33.5 & 48.9 \\
Crude lipid & 4.7 & 9.4 & 23.2 \\
Crude ash & 2.4 & 9.2 & 10.8 \\
Moisture & 74.3 & 41.0 & 3.1 \\
\hline Dry matter basis weight $(\mathrm{g} / \mathrm{l00} \mathrm{g})$ & & & \\
$\quad$ Crude protein & 72.3 & 56.8 & 50.5 \\
Crude lipid & 18.2 & 16.0 & 23.9 \\
\hline $\mathrm{n}$-3 HUFA & 4.5 & 2.4 & 5.5 \\
\hline Vitamin A (IU $/ \mathrm{g})$ & 24.5 & 26.0 & 5.8 \\
Vitamin E $(\mu \mathrm{g} / \mathrm{g})$ & trace & 471.8 & 124.1 \\
\hline
\end{tabular}

spawning results, especially the total egg production. The condition factor, a relationship between body weight and body length of brood fish, was almost same among the groups (brood male: 18.6-19.7, brood female: 19.1-20.5), although it was slightly higher in male and female brood fish fed SDP compared to other groups. However, it was found that the condition factors of brood fish used in this experiment were still lower than those obtained from both wild and cultured yellowtail used as spawner in practice. ${ }^{2,5,6)}$ In order to assess the maturity, egg diameter was determined under the stereoscopic microscope after collecting eggs by inserting a cannula into the genital pore of the female brood fish of each group. This examination revealed a difference in size and the diameter of eggs; those obtained from the RF group (300-500 $\mu \mathrm{m})$ were smaller than those from the MP or the SDP groups $(600-700 \mu \mathrm{m})$. This might probably have affected the spawning and quality of eggs in the RF group.

The first spawning occurred in brood fish fed MP and SDP, two days after $\mathrm{HCG}$ injection and continued for 10 and 8 days, respectively, whereas the RF group spawned only once at the end of the spawning period. In practice, although eggs were usually successfully collected after induced spawning of broodstock yellowtail fed on raw fish, ${ }^{2)}$ the fish of the RF group in our experiment were not stimulated by the HCG injection. This might be due to the

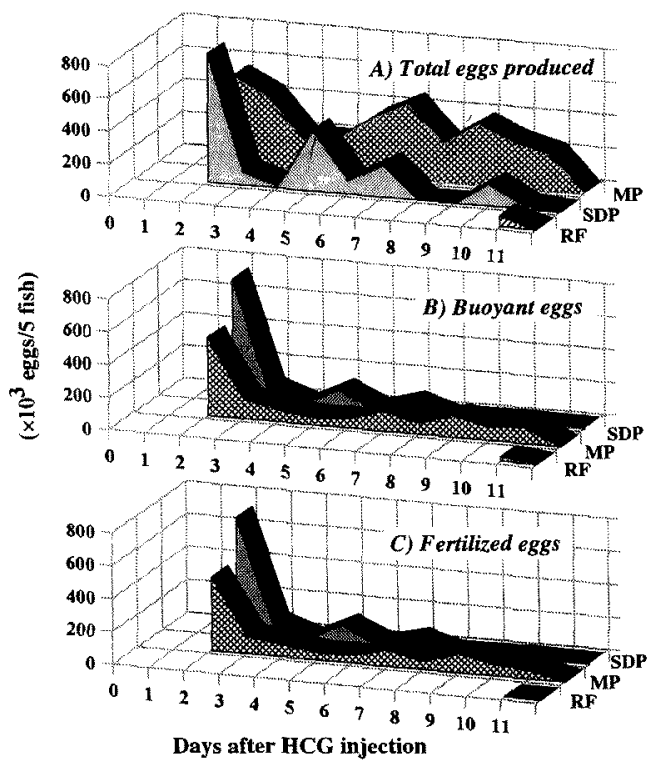

Fig. 2. Results of spawning by yellowtail broodstock fed RF, MP or SDP for $2 \frac{1}{2}$ months (production from 5 females)

Table 3. Status of the broodstock after the $2 \frac{1}{2}$ month feeding experiment ${ }^{*}$

\begin{tabular}{|c|c|c|c|c|c|c|}
\hline & \multicolumn{6}{|c|}{ Experimental groups } \\
\hline & \multicolumn{2}{|c|}{ RF } & \multicolumn{2}{|c|}{ MP } & \multicolumn{2}{|c|}{ SDP } \\
\hline & Male & Female & Male & Female & Male & Female \\
\hline Body weight (kg) & $4.2 \pm 0.4$ & $4.3 \pm 0.3$ & $3.8 \pm 0.1$ & $3.8 \pm 0.6$ & $4.0 \pm 0.3$ & $4.3 \pm 0.3$ \\
\hline Fork length (cm) & $60.5 \pm 1.5$ & $60.2 \pm 1.5$ & $58.8 \pm 1.3$ & $58.2 \pm 2.6$ & $58.6 \pm 2.3$ & $59.4 \pm 1.7$ \\
\hline Condition factor ${ }^{* 2}$ & $19.0 \pm 1.1$ & $19.6 \pm 0.8$ & $18.6 \pm 0.9$ & $19.1 \pm 1.6$ & $19.7 \pm 1.2$ & $20.5 \pm 1.1$ \\
\hline
\end{tabular}

*1 Mean $\pm S D, n=5$.

*2 $_{2}$ (Body weight $\left.\times 1000\right) /\left(\right.$ Fork length). ${ }^{3)}$ 
Table 4. Effect of broodstock diets on the spawning and egg quality of yellowtail

\begin{tabular}{|c|c|c|c|c|}
\hline & & \multicolumn{3}{|c|}{ Experimental groups } \\
\hline & & RF & MP & SDP \\
\hline Spawning duration & (days) & 1 & 10 & 8 \\
\hline \multicolumn{5}{|l|}{ Eggs } \\
\hline Eggs produced/fish ${ }^{*}$ & $\left(\times 10^{3}\right)$ & 13 & 652 & 333 \\
\hline Buoyancy rate & $(\%)$ & 35.7 & 39.0 & 59.2 \\
\hline Fertilization rate ${ }^{*_{2}}$ & $(\%)$ & 3.0 & 33.8 & 56.9 \\
\hline Abnormal eggs*3 & $(\%)$ & 8.1 & 13.8 & 17.1 \\
\hline Egg diameter $^{*_{4}}$ & $(\mu \mathrm{m})$ & $1083 \pm 14$ & $1126 \pm 50$ & $1124 \pm 56$ \\
\hline Oil-globule diameter ${ }^{*}$ & $(\mu \mathrm{m})$ & $268 \pm 9$ & $295 \pm 14$ & $303 \pm 13$ \\
\hline \multicolumn{5}{|l|}{ Hatched larvae } \\
\hline Larvae obtained/fish & $\left(\times 10^{3}\right)$ & $\mathrm{nd}^{* 5}$ & 105 & 143 \\
\hline Total hatching rate ${ }^{* 6}$ & $(\%)$ & nd & 17.7 & 46.9 \\
\hline \multicolumn{5}{|c|}{$\begin{array}{l}\text { * The average values from } 5 \text { females which were stocked in each experimental } \\
\text { tank. } \\
\text { * }_{2} \text { Out of the total eggs produced. } \\
\text { * }_{3} \text { Eggs with two or more oil-globules. } \\
\text { * }_{4} \text { Mean } \pm \mathrm{SD}, \mathrm{n}=50 \text {. } \\
\text { * }_{5} \text { Not determined because of poor egg production. } \\
\text { * }_{6} \text { Based on total eggs produced, reducing the numbers removed during sam- } \\
\text { pling. }\end{array}$} \\
\hline
\end{tabular}

smaller size of eggs prior to hormone injection (300-500 $\mu \mathrm{m})$, suggesting the necessity of prolonged feeding to increase the ovarian maturation of this group. ${ }^{4,6)}$ The HCG stimulation finally succeeded in the group, albeit a ten-day delay (Fig. 2). Table 4 shows the results of spawning by yellowtail broodstock fed different test diets. Through the 10 days of the spawning period, brood fish of the MP group produced $652 \times 10^{3}$ eggs per female; of which $39.0 \%$ buoyant eggs and $33.8 \%$ of total eggs were fertilized. The SDP group produced $333 \times 10^{3}$ eggs per female; $59.2 \%$ were buoyant eggs and $56.9 \%$ of the total were fertilized. The RF group which spawned only once produced $13 \times 10^{3}$ eggs per female, $35.7 \%$ were buoyant eggs and only as low as $3.0 \%$ were fertilized. On the total production profile, brood fish fed MP spawned eggs twofold of the SDP group, but still these values were lower than those hitherto reported.6) The lower production of the MP and SDP groups might be attributed to the size of broodstock used, as described earlier. In fact, the broodstock of the very same groups which were further cultured for another year successfully produced a large number of eggs, comparable to those obtained in the practical mass seed-production operations. ${ }^{2), * 3}$ Therefore, the spawning performances obtained from yellowtail broodstock weighing only about 4 $\mathrm{kg}$ in this study should be evaluated on the basis of criteria such as buoyancy and fertilization rate, rather than the total egg production, as reported for turbot ${ }^{11)}$ or red sea bream. ${ }^{12,13)}$ In our experiment, the total egg production was high in the MP group than the SDP group, but the rate of buoyant and fertilized eggs was higher in the latter as graphically presented in Fig. 4. This result suggested that quality of eggs obtained from broodstock fed SDP was higher than that from the MP group.

The size of eggs and oil-globule diameter of the MP group (egg: $1126 \mu \mathrm{m}$, oil-globule: $295 \mu \mathrm{m}$ ) were not differ-

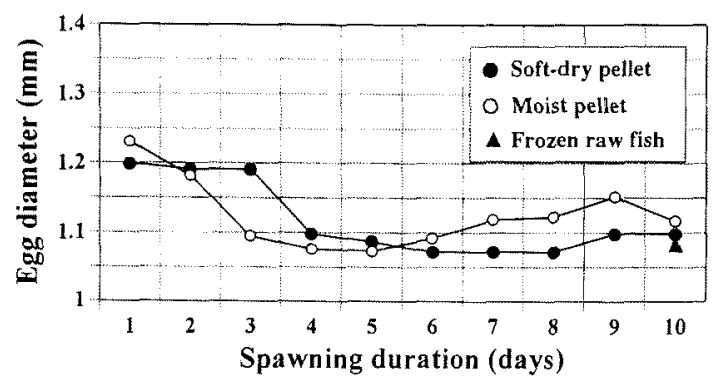

Fig. 3. Changes in egg diameter of yellowtail during the spawning period.

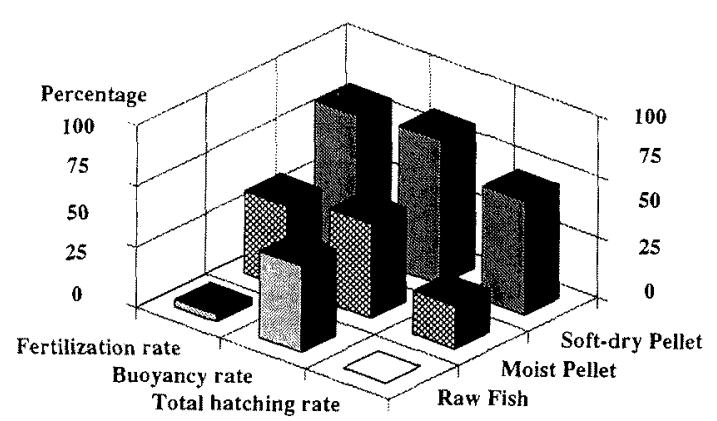

Fig. 4. Effect of broodstock diets on quality of eggs from yellowtail fed RF, MP or SDP for $2 \frac{1}{2}$ months prior to spawning.

ent from those obtained from the SDP group (egg: 1124 $\mu \mathrm{m}$, oil-globule: $303 \mu \mathrm{m}$ ) and both were higher than those from the RF group (egg: $1083 \mu \mathrm{m}$, oil-globule: $268 \mu \mathrm{m}$ ). Additionally, both egg and oil-globule diameters observed in the MP and SDP groups were comparable with those produced by broodstock prepared from wild yellowtail (egg: 1150-1440 $\mu \mathrm{m}$, oil-globule: $240-370 \mu \mathrm{m}$ ). ${ }^{14}$ ) In general, fecundity of brood fish and egg size tend to be inversely related, ${ }^{15)}$ but the diameter of eggs obtained from yellowtail by the hormonal inducement method in this experiment was not inversely proportional to the total amount of eggs produced, as noted for rainbow trout ${ }^{16)}$ and red sea bream. ${ }^{17)}$ Regardless of the results of RF group, it was found that the size of eggs gradually decreased as the spawning advanced in both the SDP group ( $1199 \mu \mathrm{m}$ down to $1098 \mu \mathrm{m})$ and the MP group $(1231 \mu \mathrm{m}$ down to 1117 $\mu \mathrm{m})$ as shown in Fig. 3. These findings agreed with the results obtained in yellowtail by Mushiake $e t$ al. ${ }^{6)}$ and in other marine finfish such as red sea bream ${ }^{18)}$ and Japanese striped knifejaw. ${ }^{19)}$ However, the percentage of abnormal eggs (eggs with two or more oil globules) in the SDP and MP groups (17.1 and 13.8 respectively) were higher compared to the RF group (8.1).

Besides the rate of egg-fertilization, the hatching rate was also determined for buoyant eggs obtained on each spawning-day of both the MP and SDP groups, but not for the RF group where the egg production was poor, necessitating the preservation of all eggs for the chemical assessment. The number of larvae obtained and the hatching rate of total eggs produced were higher in the SDP

\footnotetext{
${ }^{*}{ }_{3}$ V. Verakunpiriya, K. Watanabe, K. Mushiake, K. Kawano, T. Kobayashi, I. Hasegawa, and T. Watanabe: Abst. Metg. Japan Soc. Fisheries Sci., Oct., 1994, p. 79 (in Japanese).
} 
Table 5. Spawning performance and the quality of eggs produced at the different phases ${ }^{{ }^{*}}$ of spawning period by yellowtail broodstock fed the experimental diets

\begin{tabular}{|c|c|c|c|c|c|c|c|c|}
\hline & & \multirow{2}{*}{$\frac{\text { Raw fish }}{\text { Initial }}$} & \multicolumn{3}{|c|}{ Moist pellet } & \multicolumn{3}{|c|}{ Soft-dry pellet } \\
\hline & & & Initial & Middle & Final & Initial & Middle & Final \\
\hline Eggs produced/fish & $\left(\times 10^{3}\right)$ & 12.6 & 230.2 & 201.4 & 220.8 & 187.0 & 127.2 & 29.8 \\
\hline Buoyancy rate & $(\%)$ & 35.7 & 58.2 & 22.4 & 34.0 & 85.7 & 27.5 & 5.9 \\
\hline Fertilization rate ${ }^{* 2}$ & $(\%)$ & 8.5 & 53.8 & 19.2 & 21.1 & 89.2 & 25.6 & 4.6 \\
\hline Egg diameter & $(\mu \mathrm{m})$ & $1083 \pm 14$ & $1169 \pm 69$ & $1080 \pm 10$ & $1128 \pm 16$ & $1195 \pm 6$ & $1086 \pm 13$ & $1098 \pm 27$ \\
\hline Oil-globule diameter & $(\mu \mathrm{m})$ & $268 \pm 9$ & $297 \pm 19$ & $282 \pm 5$ & $303 \pm 10$ & $318 \pm 2$ & $292 \pm 5$ & $309 \pm 11$ \\
\hline Larvae obtained/fish & $\left(\times 10^{3}\right)$ & $-^{* 3}$ & 100.2 & 2 & 3 & 141 & 2.4 & $-{ }^{* 3}$ \\
\hline Total hatching rate ${ }^{*_{4}}$ & $(\%)$ & $-^{* 3}$ & 49.5 & 1.0 & 2.1 & 89.5 & 22.5 & $-*^{* 3}$ \\
\hline
\end{tabular}

${ }^{*}$ The eggs obtained from the 1 st-3rd day, 4th-6th day and 7th-10th day of the spawning period, were classified as belonging to the initial, middle and final phases, respectively.

*2 Out of total eggs produced.

* Not determined.

${ }^{*}$ Based on total eggs produced, reducing the numbers removed during sampling.

group $\left(143 \times 10^{3}\right.$ larvae/female; $46.9 \%$ total hatch) compared to the MP group $\left(105 \times 10^{3}\right.$ larvae/female; $17.7 \%$ total hatch) as shown in Table 4 and Fig. 4. The rate of total hatch of the SDP group was also found to be superior to that obtained in yellowtail fed moist pellet by Mushiake et al. ${ }^{6}$ (18.2-25.6\% total hatch).

As already reported by Mushiake et al. ${ }^{2,5,6)}$ there is a general fluctuation in the production and quality of eggs during the spawning period, being the widest on the 1st spawning-day and thereafter gradually narrowing as the days lapse. Therefore, the spawning period in this study was separated into three phases in order to compare the results more precisely between the treatments: initial phase - eggs obtained from the 1st to the 3rd day; middle phase - those obtained from the 4th to the 6th day; and final phase - eggs obtained from the 7th to the 10th day of the spawning period. As shown in Table 5 and Fig. 2, the spawning performance and egg quality in both the MP and SDP groups were highest at the initial phase, notably so on the 1st day of this phase. There was a drop in total egg production in the two latter phases within the MP group, even though the production in the final phase was slightly higher than middle phase. A similar fall was observed in the number of buoyant and fertilized eggs and egg size. A sudden drop was also found in total hatching rate for this group. Almost identical, but more distinct reduction patterns were also noted in the SDP group, unlike in red sea bream $^{13,16-18,20)}$ where similar observations were made in the middle phases of the spawning period. Generally, the better egg quality in the initial phase (Table 5) or on the 1st day (Table 6) of spawning period was more prominently observed in the SDP than the MP group.

The results of spawning in the present study have shown that yellowtail broodstock fed extruded dry pellets from juvenile stage could attain maturity and subsequently spawn. It is therefore evident that SDP could be employed as broodstock diets for yellowtail and that use of SDP would overcome the drawbacks of the MP mentioned earlier. Moreover, SDP seemed to be superior to MP as figured out by the quality of eggs, although the total egg production in this trial was lower than the MP group. The difference in egg quality between the SDP and the MP groups might be related in part to dietary carotenoids. The
Table 6. Spawning performance and the quality of eggs obtained on the 1st day of spawning from yellowtail broodstock fed the experimental diets

\begin{tabular}{llccc}
\hline & & \multicolumn{3}{c}{ Experimental groups } \\
\cline { 3 - 5 } & & $\mathrm{RF}$ & $\mathrm{MP}$ & $\mathrm{SDP}$ \\
\hline Eggs & & & & \\
Eggs produced $/$ fish $^{*_{1}}$ & $\left(\times 10^{3}\right)$ & 13 & 107 & 156 \\
Buoyancy rate & $(\%)$ & 35.70 & 89.17 & 92.59 \\
Fertilization rate & $(\%)$ & 3.00 & 83.05 & 89.31 \\
Egg diameter & $(\mu \mathrm{m})$ & $1083 \pm 14$ & $1231 \pm 83$ & $1199 \pm 52$ \\
Oil-globule diameter* & $(\mu \mathrm{m})$ & $268 \pm 9$ & $310 \pm 20$ & $316 \pm 11$ \\
\hline Hatched larvae & & & & \\
Larvae obtained/fish & $\left(\times 10^{3}\right)$ & nd & 77 & 132 \\
Total hatching rate & $(\%)$ & nd & 76.38 & 87.79 \\
\hline
\end{tabular}

* The average values from 5 females which were stocked in each experimental tank.

*2 Out of the total eggs produced.

*3 Mean $\pm \mathrm{SD}, \mathrm{n}=50$.

$*_{4}$ Not determined because of poor egg production.

*5 Based on total eggs produced, reducing the numbers removed during sampling.

$10 \%$ krill meal component in the SDP may be responsible for this, as described in the earlier research by Watanabe $e t$ $a l .{ }^{21,223}$ who had indicated the effectiveness of raw krill in terms of astaxanthin for enhancement of red sea bream egg quality. The $\beta$-carotene mis-supplemented to the MP in place of astaxanthin might not have contributed to egg quality improvement as indicated in red sea bream by Watanabe et ${ }^{1{ }^{18)}}{ }^{81}$ In the bio-chemical examination, focusing on carotenoids, we observed certain relationships between the diets and egg quality. This will be discussed in another paper.

\section{References}

1) T. Watanabe: Past and present approaches to aquaculture waste management in Japan, in "Nutritional Strategies \& Aquaculture Waste" (ed. by C. B. Cowey and C. Y. Cho), Fish Nutrition Research Laboratory, University of Guelph, Canada, 1991, pp. 137-154.

2) K. Mushiake, S. Arai, A. Matsumoto, H. Shimma and I. Hasega- 
wa: Artificial insemination from 2 year-old cultured yellowtail fed with moist pellets. Nippon Suisan Gakkaishi, 59, 1721-1726 (1993).

3) T. Watanabe, H. Sakamoto, M. Abiru and J. Yamashita: Development of a new type of dry pellet for yellowtail. Nippon Suisan Gakkaishi, 57, 891-897 (1991).

4) S. Umeda: Yellowtail, in "Reproductive Rhythm in Marine Fish" No. 85 (ed. by K. Hirose), Koseisya-Koseikaku, Tokyo, 1991, pp. 92-100.

5) K. Mushiake, H. Fujimoto and H. Shimma: A trial of evaluation of activity in yellowtail Seriola quinqueradiata larvae. Suisan Zoshoku, 41, 339-344 (1993).

6) K. Mushiake, K. Kawano, W. Sakamoto and I. Hasegawa: Effect of extended daylength on ovarian maturation and HCG-induced spawning in yellowtail fed moist pellets. Fisheries Sci., 60, 647-651 (1994).

7) T. Fujita, M. Satake, S. Nikichi, M. Takeda, S. Shimeno, H. Kuwabara, W. Miki, K. Yamaguchi and S. Konosu: Pigmentation of cultured yellowtail with krill oil. Nippon Suisan Gakkaishi, 49, 1595-1600 (1983).

8) T. Takeda: Diet for marine fish, in "Fish Nutrition and Diet" (ed. by the Japanese Society of Scientific Fisheries), Vol. 54, KoseishaKouseikaku, Tokyo, 1985, pp. 112-122.

9) M. Takeda, S. Shimeno, H. Hosokawa, H. Kajiyama and T. Kaisyo: The effect of dietary calorie-to-protein ratio on growth, feed conversion and body composition of young yellowtail. Nippon Suisan Gakkaishi, 41, 443-447 (1975).

10) S. Shimeno: Yellowtail, Seriola quinqueradiata, in "'Handbook of Nutrient Requirement of Finfish" (ed. by R. P. Wilson), CRC Press, 1991, pp. 181-192.

11) L. A. McEvoy: Ovulatory rhythms and over-ripening of eggs in cultivated turbot, Scophthalmus maximus L. J. Fish. Biol., 24, 437448 (1984).

12) K. Sakai, M. Nomura and F. Takashima: Characteristics of naturally spawned eggs of red sea bream. Nippon Suisan Gakkaishi, 51, 1395-1399 (1985).

13) T. Watanabe, T. Arakawa, C. Kitajima and S. Fujita: Effect of
Nutritional quality of broodstock diets on reproduction of red sea bream. Nippon Suisan Gakkaishi, 50, 495-501 (1984).

14) A. Tsujigado: Yellowtail Seriola quinqueradiata, in "Modern Methods of Aquaculture in Japan" (ed. by H. Ikenoue and T. Kafuku), Elsevier, Japan, 1992, pp. 131-143.

15) J. H. S. Blaxter: Development: Eggs and larvae, in "Fish Physiology" Vol. 3 (ed. by W. S. Hoar and D. J. Randall), Academic Press, New York, 1969, pp. 177-252.

16) M. Nomura: Studies on reproduction of rainbow trout Salmo gairdneri with special references to egg taking-IV The fecundity or number and weight of eggs taken. Nippon Suisan Gakkaishi, 29, 325-335 (1963).

17) T. Watanabe, A. Itoh, C. Kitajima and S. Fujita: Effect of dietary protein levels on reproduction of red sea bream. Nippon Suisan Gakkaishi, 50, 1015-1022 (1984).

18) T. Watanabe, A. Itoh, A. Murakami, Y. Tsukashima, C. Kitajima and S. Fujita: Effect of nutritional quality of diets given to broodstock on the verge of spawning on reproduction of red sea bream. Nippon Suisan Gakkaishi, 50, 1023-1028 (1984).

19) K. Itoh: Collecting eggs by spontaneous spawning and hatching of larvae in Japanese striped knifejaw. Saibai Giken, 7, 5-12 (1978).

20) T. Watanabe, T. Koizumi, H. Suzuki, S. Satoh, T. Takeuchi, N. Yoshida, T. Kitada and Y. Tsukashima: Improvement of quality of red sea bream eggs by feeding broodstock on a diet containing cuttlefish meal or on raw krill shortly before spawning. Nippon Suisan Gakkaishi, 51, 1511-1521 (1985).

21) T. Watanabe, T. Fujimura, M-J. Lee, K. Fukusho, S. Satoh and T. Takeuchi: Effect of polar and nonpolar lipids from krill on quality of eggs of red sea bream Pagrus major. Nippon Suisan Gakkaishi, 57, 695-698 (1991).

22) T. Watanabe, M-J. Lee, J. Mizutani, T. Yamada, S. Satoh, T. Takeuchi, N. Yoshida, T. Kitada and T. Arakawa: Effective components in cuttlefish meal and raw krill for improvement of red sea bream Pagrus major eggs. Nippon Suisan Gakkaishi, 57, 681-694 (1991). 